\title{
CONSERVATIVE MANAGEMENT OF ACUTE LUMBAR DISC HERNIATION WITH ASSOCIATED RADICULOPATHY: A STUDY
}

\author{
RAPPAI TJ ${ }^{1}$, SURENDER ${ }^{2}$, NEERAV PORWAL ${ }^{3}$, ASHOK KUMAR ${ }^{1 *}$, SAPNA CHAUHAN ${ }^{4}$
}

${ }^{1}$ Department of Neurosurgery, Surgical Division, Command Hospital, Lucknow, Uttar Pradesh, India. ${ }^{2}$ Department of Anaesthsia, Muzaffarnagar Medical College, Muzaffarnagar, Uttar Pradesh, India. ${ }^{3}$ Department of Neurosurgery, Surgical Division, Command Hospital, Chandimadir, Haryana, India. ${ }^{4}$ Department of Microbiology, Muzaffarnagar Medical College, Muzaffarnagar, Uttar Pradesh, India. Email: ashoktanwar8695@gmail.com

Received: 30 August 2021, Revised and Accepted: 10 November 2021

\section{ABSTRACT}

Objective: Acute disc herniation (DH) is a common cause of low back pain (LBP). It ranks fifth in the category of diseases in terms of cost of hospital care. It has higher indirect costs due to absenteeism from work and disability than any other disease. The present study was performed to assess the clinical outcomes of non-surgically treated LBP patients after 6 months of follow-up.

Methods: The present study was prospective study which was performed on 450 lumbar radicular patients visiting the neurosurgery outpatient department having clinical signs and symptoms of acute lumbar DH of less than 3 month duration. Their diagnosis was confirmed by magnetic resonance imaging. The patients were treated conservatively during 6 months. Pain and disability were assessed by visual analog scale (VAS) and Oswestry disability questionnaire, respectively.

Results: About 135 (30\%) female and 315 (70\%) male participated in the study. During the follow-up period, 27 (06\%) patients (21 male and 6 female) showed poor response to conservative treatment and motor weakness and underwent surgical intervention. A significant improvement in the VAS Score was seen after 6 months of conservative treatment than initial evaluation of patients $(3.12 \pm 1.84,7.1 \pm 1.43$, $p=0.00)$. Furthermore, significant improvement in disability score of patients was seen in follow-up period $(25.82 \pm 16.92,53.66 \pm 17.66 ; p=0.00)$.

Conclusion: Results of our study showed that conservative treatment in patients of acute lumbar DH have significant improvement in pain relief and disability without any notable side effect.

Keywords: Conservative treatment, Low back pain, Disc herniation, Lumbar radicular pain.

(C) 2021 The Authors. Published by Innovare Academic Sciences Pvt Ltd. This is an open access article under the CC BY license (http://creativecommons.org/ licenses/by/4.0/) DOI: http://dx.doi.org/10.22159/ajpcr.2021v14i12.43020. Journal homepage: https://innovareacademics.in/journals/index.php/ajpcr

\section{INTRODUCTION}

Low back pain (LBP) is a common-condition in younger than 50 years of age. The economic burden of lumbar-spine disorders is heavy [1]. It ranks fifth in the category of diseases in terms of cost of hospital care. It has higher indirect costs due to absenteeism from work and disability than any other disease [2]. LBP due to acute lumbar disc herniation (DH) is common disorder at the ages of $40-50$ year. Main symptom being radiating pain in the area of the leg typically served by one nerve root in the lumbar or sacral spine [1,2]. Several treatment modalities including surgical and conservative are being applied for these patients. Cauda equina syndrome is the single absolute indication for surgery in a LBP patient [3-5]. Maximum patients of acute DH improved with conservative treatment such as bed rest, life style modification, medication, back support, exercise, manipulation, and physical therapy [6,7].

Different studies have reported that conservative treatment with nonsteroidal anti-inflammatory drug (NSAID) cause pain relief in patients with DH. The same studies showed that oral steroid did not have useful impacts on acute lumbar DH $[8,9]$. Some study used muscle relaxant in acute LBP [9]. Patients who were non responsive to conservative treatment or had contraindications for surgery epidural injection was tried [9-12]. The present study was performed to assess the clinical outcomes of nonsurgically treated LBP patients after 6 months of follow-up.

\section{METHODS}

The present study was prospective study which was performed on 450 lumbar radicular patients visiting the Neurosurgery outpatient department having clinical signs and symptoms of acute lumbar DH of $<3$ months duration who were confirmed by magnetic resonance imaging (MRI). All these patients were offered surgery and conservative management. Only those patients who were unwilling for surgery and opted for conservative management were included in this study. These patients were on regular follow-up at Neurosurgery clinic of Command Hospital Lucknow.

\section{Study samples}

Consecutive sampling of patients was done. Consent both verbal and written was obtained from all patients. All patients were assessed by neurologic and lumbar movement examination, detection of muscle force and straight leg raising test (SLR). MRI was done for all patients and if they had DH, they were included in this study. Patients with degenerative or spinal canal stenosis, tumor, trauma, infection, spondylolysthesis or signs and symptoms of neurologic deficit were excluded from the present study.

\section{Study design}

All patients were visited by neurosurgeon; and MRI imaging studies were used for diagnosis confirmation. An independent research physician verified symptoms and signs of selected patients at the time of enrollment. Patients with acute lumbar DH were included. Clinical evaluations was performed by SLR test, muscle strength, reflexes (Patellar and Achilles), sensory changes, the Oswestry Disability Questionnaire (ODQ), 100-mm visual-analogue scale initially and after following for 6 months.

\section{Study period}

A prospective study was conducted for 24 months from April 2019 to March 2021. 


\section{Conservative treatment}

After initial evaluation of each patient conservative treatments such as life style modification, bed rest, drug therapy with NSAIDs, muscle relaxant, triyclic antidepressants, and physiotherapy were prescribed.

\section{Statistical analysis}

Mann-Whitney and Wilcoxon test were used to analyze study data using SPSS software 14.0. Significant difference between study variables was detected using Two-tailed significance level of 0.05 .

\section{RESULTS}

About 135 (30\%) female and 315 (70\%) male included in the study. 252 patients (56\%) had disc extrusion (DE) and $198(44 \%)$ patients had DH. The most affected level in patients with DE and DH was L4-L5 (Table 1). A significant improvement in the visual analog scale (VAS) Score was seen after 6 months of conservative treatment than initial evaluation of patients $(3.12 \pm 1.84,7.1 \pm 1.43, \mathrm{p}=0.00)$ (Table 2 ).

Significant difference in evaluation of DE and DH patients was not seen initially $(7.42 \pm 1.23,6.68 \pm 1.58 ; \mathrm{p}=0.09)$ and after 6 months follow-up $(2.70 \pm 1.51,3.57 \pm 2.08$; $p=0.15)$. However, $18(66.6 \%)$ of 27 patients who underwent surgical intervention were DE as compared to 9 (33.3) DH patients. No significant difference in mean of VAS in male and female patients was seen in initial $(6.83 \pm 1.51,7.50 \pm 1.23$; $p=0.12)$ and after 6 months of follow-up evaluation $(2.87 \pm 1.87,3.41 \pm 1.76$; $\mathrm{p}=0.22)$.

Conservative treatments for 6 months significantly improved Oswestry Disability Score in study patients $(25.82 \pm 16.92,53.66 \pm 17.66$; $p=0.00)$ (Table 2). After initial evalution, mean of Oswestry Disability Score was significantly higher in DE Patients than DH patients $(58.42 \pm 18.81$, $47.36 \pm 14.17 ; \mathrm{p}=0.03$ ) but this difference was not seen after conservative treatment of 6 months $(24.91 \pm 14.49,26.85 \pm 17.76$; $\mathrm{p}=0.758)$.

Mean of SLR degree in study patients after 6 months follow-up significantly improves in comparison with initial evaluation $(68.22 \pm 15.67,43 \pm 11.93 ; p=0.00)$. In initial evaluation DE patients had no significant difference in mean of SLR degree as compared to DH patients $(41.25 \pm 10.05,43.40 \pm 13.92 ; \mathrm{p}=0.66)$ and same was also seen after 6 months of follow-up $(67.91 \pm 14.36,68.57 \pm 17.40 ; p=0.88)$. Oswestry Disability Score mean had significant difference between patients of two groups in initially $(p=0.032)$. VAS and SLR degree mean did not show a significant difference in patients with surgical and conservative treatment.

\section{DISCUSSION}

In the present study, all the patients were followed up for 6 months. Only 27 patients required surgical intervention as they were unresponsive to conservative treatment and showed progressive muscle weakness. The severity of pain as measured by VAS was one of the patient outcome predictor significantly improved after 6 months conservative treatment

Table 1: Level of DHs in our patients

\begin{tabular}{lllll}
\hline $\begin{array}{l}\text { Level/type } \\
\text { of DH/DE }\end{array}$ & $\begin{array}{l}\text { L3-L4 } \\
\mathbf{n}(\mathbf{\%})\end{array}$ & $\begin{array}{l}\text { L4-L5 } \\
\mathbf{n}(\%)\end{array}$ & $\begin{array}{l}\text { L5-S1 } \\
\mathbf{n}(\%)\end{array}$ & $\begin{array}{l}\text { Total } \\
\mathbf{n}(\%)\end{array}$ \\
\hline DH & $9(4.5)$ & $126(63.6)$ & $63(31.8)$ & $198(44)$ \\
DE & $9(3.6)$ & $126(50.0)$ & $117(46.4)$ & $252(56)$ \\
Total & $18(4.0)$ & $252(56.0)$ & $180(40.0)$ & $450(100)$ \\
\hline
\end{tabular}

DE: Disc extrusion, DH: Disc herniation

Table 2: Change of VAS and ODIS at baseline and after 6 months of treatment

\begin{tabular}{lll}
\hline & VAS change & ODIS \\
\hline Baseline & $(7.1 \pm 1.43)$ & $(53.56 \pm 17.66)$ \\
After 6 months & $(3.12 \pm 1.84) \mathrm{p}<0.0001$ & $(25.88 \pm 16.99) \mathrm{p}<0.0001$ \\
\hline
\end{tabular}

VAS: Visual analog scale, ODIS: Oswestry Disability index score than initial evaluation. Peul et al. in their study evaluated surgery versus prolonged conservative treatment for sciatica for a period of 1 year, they reported that pain relief was achieved in $1^{\text {st }}-26^{\text {th }}$ week of conservative treatment [12]. The present study also demonstrated that the clinical outcome in patients with acute lumbar $\mathrm{DH}$ who were treated conservatively was similar to those who were treated surgically after 6 month of follow-up. However, the patient who had early surgery their recovery rate and pain relief was faster. Ahn et al. reported that VAS and Oswestry Disability scoring showed a greater change in the sequestrated group than other group. Patients can be treated successfully by conservative treatment and outcomes in central extruded DH patients were as good as sequestered DH [13]. Owlia et al. in their study on lumbar radicular pain found that pain relief was achieved in $75 \%$ of all the patients when treated conservatively with epidural injection after 1 month of follow-up [14]. Pearson et al. in their study found that discectomy had better results in improvement of back pain than conservative treatment and this difference was maintained for 2 years [15]

Oswestry Disability Score in our study improved significantly with conservative treatment in 6 month follow-up period. In initial evaluation significant difference between mean of Oswestry Disability Score in two types of herniation (DE and DH) was seen. However, this significant difference wasn't seen after 6 months follow-up. Ahn et al. and Weinstein et al. in their studies have shown significant improvement in the Oswestry Disability Score in patients with acute lumbar DH on conservative treatment $[13,16]$. Masui et al. performed their study on 21 lumbar disk herniation patients who were treated non-surgically and were followed for a minimum of 7 years. They investigated patients' clinical outcomes at the initial, 2-year follow-up. MRI study showed that clinical outcome did not depend on the size of herniation or the grade of degeneration of the intervertebral disc in the minimum 7 year follow-up [17].

Mean of SLR degree after 6 months follow-up significantly improved than initial evaluation. Mean of Oswestry Disability Score had significant difference between patients of conservative treatment and surgery treatment. Despite small number of studied cases and rather short period of follow-up, this study is in concordance with the similar studies.

Limitations of the present study are, firstly randomization of samples was not done in our study. Secondly, we assessed the pain and disability by VAS and ODQ $\mathrm{s}$ in our patients, other methods may show different results. The favorable outcomes associated with the conservative management in DHs should be further confirmed in controlled trials.

\section{CONCLUSION}

According to the results of our study, conservative treatment in patients with acute lumbar DH causes significant pain relief and disability improvement without any notable side effects. Conservative management with proper patient selection can reduce risk of inappropriate surgery in patients with lumbar DH. There is no relationship between clinical outcome at the end of 6 months of conservative treatment and type of $\mathrm{DH}$ in the initial evaluation. About $94 \%$ of patient with conservative treatment clinical improvement was seen. Oswestry Disability Score can be a good prognostication indicator for future surgery operations.

\section{ACKNOWLEDGMENT}

The authors would like to thank the Department of Radiodiagnosis and Imaging, Command Hospital, Lucknow and all the team members who supported while preparing this article.

\section{AUTHORS' CONTRIBUTIONS}

All the cases presented in the current study were clinically evaluated by Ashok Kumar and TJ Rappai. Ashok Kumar, Neerav Porwal, 
Surender, and TJ Rappai made a substantial contribution in conception, acquisition of data, interpretation of data, in drafting the article and revising it for ensuring critical academic content and agreed to be held accountable for all aspects of the work.

\section{CONFLICTS OF INTEREST}

The authors declare that there are no conflicts of interest related to this study.

\section{AUTHORS' FUNDING}

The author(s) received no specific funding for this work.

\section{REFERENCES}

1. Cherkin DC, Deyo RA, Loeser JD, Bush T, Waddell G. An international comparison of back surgery rates. Spine (Phila Pa 1976) 1994;19:1201-6.

2. van Tulder MW, Koes BW, Bouter LM. A cost-of-illness study of back pain in The Netherlands. Pain 1995;62:233-40.

3. Hardy R, Ball P. Treatment of disk disease of the lumbar spine. In: Winn HR, editor. Youmans Neurological Surgery. $5^{\text {th }}$ ed. Philadelphia, PA: Saunders; 2004.

4. Ropper A, Brown R. Pain in the back, Neck and extremities. In: Ropper A, Brown R, editors. Asams and Victor's Principles of Neurology. New York: McGraw Hill; 2005.

5. McCormick P. Intervertebral discs and radiculopathy. In: Rowland L, Lippincott W, editors. Merritt's Neurology. New York: Neurological Institute; 2005.

6. Welch WC, Gerszten PC. Alternative strategies for lumbar discectomy: Intradiscal electrothermy and nucleoplasty. Neurosurg Focus 2002;13:E7.

7. Rozen D, Grass G. Interventional pain medicine approaches to nonradicular low back pain of internal disc disruption origin. Pain Physician 2005;8:399-409.

8. Pengel LH, Herbert RD, Maher CG, Refshauge KM. Acute low back pain: Systematic review of its prognosis. BMJ 2003;327:323.

9. Saal JA. Natural history and nonoperative treatment of lumbar disc herniation. Spine (Phila Pa 1976) 1996;21:2S-9.

10. Rivest C, Katz JN, Ferrante FM, Jamison RN. Effects of epidural steroid injection on pain due to lumbar spinal stenosis or herniated disks: A prospective study. Arthritis Care Res 1998;11:291-7.

11. Wang JC, Lin E, Brodke DS, Youssef JA. Epidural injections for the treatment of symptomatic lumbar herniated discs. J Spinal Disord Tech 2002; 15:269-72.

12. Peul WC, van Houwelingen $\mathrm{HC}$, van den Hout WB, Brand $\mathrm{R}$, Eekhof JA, Tans JT, et al. Surgery versus prolonged conservative treatment for sciatica. N Engl J Med 2007;356:2245-56.

13. Ahn SH, Park HW, Byun WM, Ahn MW, Bae JH, Jang SH, et al. Comparison of clinical outcomes and natural morphologic changes between sequestered and large central extruded disc herniations. Yonsei Med J 2002;43:283-90.

14. Owlia MB, Salimzadeh A, Alishiri G, Haghighi A. Comparison of two doses of corticosteroid in epidural steroid injection for lumbar radicular pain. Singapore Med J 2007;48:241-5.

15. Pearson AM, Blood EA, Frymoyer JW, Herkowitz H, Abdu WA, Woodward R, et al. SPORT lumbar intervertebral disk herniation and back pain: Does treatment, location, or morphology matter? Spine (Phila Pa 1976) 2008;33:428-35

16. Weinstein JN, Lurie JD, Tosteson TD, Skinner JS, Hanscom B, Tosteson AN, et al. Surgical vs nonoperative treatment for lumbar disk herniation: The spine patient outcomes research trial (SPORT) observational cohort. JAMA 2006;296:2451-9.

17. Masui T, Yukawa Y, Nakamura S, Kajino G, Matsubara Y, Kato F, et al. Natural history of patients with lumbar disc herniation observed by magnetic resonance imaging for minimum 7 years. J Spinal Disord Tech 2005; 18:121-6. 